\title{
Damage control surgery: it's evolution over the last 20 years
}

\section{Cirurgia para o controle de danos: sua evolução durante os últimos 20 anos}

\author{
Brett H Waibel, MD FACS'; Michael MF Rotondo, MD FACS'
}

A B S T R A C T

In less than twenty years, what began as a concept for the treatment of exsanguinating truncal trauma patients has become the primary treatment model for numerous emergent, life threatening surgical conditions incapable of tolerating traditional methods. Its core concepts are relative straightforward and simple in nature: first, proper identification of the patient who is in need of following this paradigm; second, truncation of the initial surgical procedure to the minimal necessary operation; third, aggressive, focused resuscitation in the intensive care unit; fourth, definitive care only once the patient is optimized to tolerate the procedure. These simple underlying principles can be molded to a variety of emergencies, from its original application in combined major vascular and visceral trauma to the septic abdomen and orthopedics. A host of new resuscitation strategies and technologies have been developed over the past two decades, from permissive hypotension and damage control resuscitation to advanced ventilators and hemostatic agents, which have allowed for a more focused resuscitation, allowing some of the morbidity of this model to be reduced. The combination of the simple, malleable paradigm along with better understanding of resuscitation has proven to be a potent blend. As such, what was once an almost lethal injury (combined vascular and visceral injury) has become a survivable one.

Key words: Patients. Wounds and injuries. Therapeutics. Surgical procedures, operative. Control.

\section{INTRODUCTION}

T he term 'Damage Control Surgery' has yet to reach twenty years of use, but the simple concepts at its core have radically changed the way critically ill patients are approached for surgery, and not just in trauma. Its beginnings were in the treatment of patients with exsanguinating abdominal injuries. The traditional approach was the same as with an elective surgery patient; definitive repair of injuries and abdominal closure in a single operative setting. The innovative change with damage control was recognition that those patients with exsanguinating injuries were not capable of such a challenge. They required an abbreviated initial laparotomy to control bleeding and contamination, followed by recovery of physiologic reserve in the intensive care unit (ICU) before definitive repair and abdominal closure at a subsequent laparotomy(ies).

While some discussions of using an abbreviated laparotomy can be found back to the American Civil War and World Wars, it was generally dismissed as poor surgical care. It was not until the 1980's, with H Harlan Stone demonstrating improved survival with abdominal packing for coagulopathic bleeding and Burch with hepatic injuries, that a more rigorous evaluation of this approach was begun ${ }^{1,2}$. Damage Control Surgery was coined in 1993, with Rotondo and Schwab's landmark paper showing a sevenfold improvement (11\% to $77 \%)$ in mortality in patients with combined visceral and major vascular injury using the damage control approach. ${ }^{3}$ Most larger series have demonstrated approximately a $60 \%$ overall survival rate with using damage control surgery techniques, though some have higher survival rates when low energy mechanisms (stabbings) predominate.

The improvement in survival for these patients comes with understanding that fundamental differences exist between the elective surgery patient and the exsanguinating trauma patient for both physiology and anatomy. The multisystem trauma patient can have injuries in multiple locations across different body cavities with loss of physiology reserve at presentation due to ongoing bleeding and contamination, which is profoundly different from the elective surgery patient who usually has a single issue without uncontrolled hemorrhage or contamination during their procedure. The exsanguinating trauma patient does not have time for optimization of medical problems, and often is unable to even give a medical history. These essential differences in presentation lead to an overall poor physiologic reserve incapable of sustaining a prolonged surgical insult. Attempting to provide a single definitive procedure in these patients leads to ongoing bleeding from coagulopathy, an unresuscitatable shock state, or multiple organ failure ${ }^{4-6}$.

In 1993, Rotondo and Schwab coined the term 'damage control surgery', demonstrated the survival benefit with it, and provided a model for its application. Over the

The Brody School of Medicine East Carolina University Greenville, North Carolina.

1. Department of Surgery Division of Trauma and Surgical Critical Care. 
following decades, refinements were made to the basic steps to produce the current model in use today ${ }^{7-10}$. At its core is the identification of patients unable to tolerate a traditional approach due to present or impending shock state, use of an abbreviate laparotomy focused only on control of bleeding and contamination to limit surgical insult and allow for aggressive resuscitation in an ICU to regain physiologic reserve. Only after correction of acidosis, hypothermia and shock are definitive repairs attempted. Closure of the abdominal wound has further been separated in the sequence; a change brought about by an emerging understanding of abdominal compartment syndrome. While the particular employment of damage control surgery may vary from patient to patient, the simple core concepts have allowed damage control surgery to be modified to other areas than trauma. Most notably, these include vascular surgery, orthopedics, and the septic abdomen 11-15. Additionally, modern military care of injured soldiers has become aligned with this model in some countries, with forward surgical teams dealing with ongoing bleeding and contamination control with definitive repair being delayed to later, rear echelon teams ${ }^{16-18}$.

\section{Indications for Damage Control Surgery}

The underlying goal is to abbreviate the initial laparotomy in those patients who would develop hypothermia, acidosis, and an acquired coagulopathy and the associated complications they bring using a more traditional approach. Therefore, the primary determinant in the need for damage control surgery should be the patient's own physiology (Table 1).

The complex interactions of multiple variables prevent absolute determinants of when damage control surgery should be performed. Critical physiological factors, such as the development of acidosis, acquired coagulopathy, hypothermia, profound hypotension/hypoperfusion, are the predominately-discussed indications for damage control surgery. Prolonged operative times (greater than 90 minutes) are also discouraged due to the high incidence of progression to physiological exhaustion.

Complex injury patterns, such as high energy blunt torso, multiple penetrating injuries, injuries across multiple compartments, or combined vascular/visceral injuries, also lend themselves to damage control approach, especially when injuries have competing priority for treatment. These injury complexes lend themselves to ongoing or recurrent hemorrhage from sites not visualized by the operative team, which can hasten the progress to physiologic exhaustion. Control of hemorrhage should be treated as a continuum across body cavities and regions with the surgeon starting at the perceived most compelling source of hemorrhage and expeditiously move to others as the situation evolves, keeping in mind the next area may not be in the current surgical field.

Finally, some injuries may be better treated with adjuncts, such as angiographic embolization of hepatic or pelvic injuries. Additionally, variation in physiological reserve exists across patient populations. The elderly and those with multiple medical comorbidities tend to have less tolerance for surgical procedures due to poor preexisting reserve. The young and athletic may hide the progression to physiologic exhaustion until hemodynamic collapse. As the surgery progresses, the need for damage control surgery should be reevaluated based upon changes in physiology balanced against the operative/treatment needs of the patient.

The adaption of damage control surgery for trauma to other areas generally resolves around identifying those patients who would develop a similar loss of physiologic reserve with intolerance to the shock state.

Table 1 - Indications for Damage Control Surgery Consideration.

A. Critical Physiological Factors

i) Hypothermia- temperature $<35^{\circ} \mathrm{C}$

ii) Acidosis- $\mathrm{pH}<7.2$ or base deficit $>8$

iii) Coagulopathy- nonmechanical bleeding, increase in prothrombin (PT) and/or partial thromboplastin time (PTT), thrombocytopenia, hypofibrinoginemia, or massive transfusion requires (> 10 units packed red blood cells [pRBC] or body volume replacement)

iv) Prohibitive operative time needed for definitive repair (> 90 minutes)

v) Hemodynamic instability or profound hypoperfusion

B. Injury Complexes Associated with Loss of Physiologic Reserve

i) High energy blunt torso trauma

ii) Multiple penetrating torso injuries

iii) Combined visceral injury with major vascular trauma

iv) Injuries across body cavities, especially those with competing treatment priorities, such as closed head injury, major vascular injury and pelvic trauma

C. Other Considerations in Trauma Patients

i) Injuries better treated with nonsurgical adjunct, such as angiographic embolization of hepatic or pelvic injuries

ii) Variation in physiologic reserve (elderly, multiple comorbidities, young, athletes) 
This is generally driven by a systemic inflammatory response from either an infectious source (septic abdomen) or second hit phenomenon stimulating an already primed immune state (damage control orthopedics). Additionally, the open abdomen techniques, commonly found with damage control surgery, lend themselves to improved effluent control while providing ease of peritoneal cavity accessibility in those patients with a septic abdomen, while reducing the potential for abdominal compartment syndrome ${ }^{13,19}$. The patient's physiology should determine the need for using damage control and open abdomen techniques.

\section{Traditional Damage Control Sequence}

When first introduced, damage control surgery was described with the three main steps, abbreviated laparotomy (part 1), ICU resuscitation (part 2), and later definitive repair (part 3). Addition of a prehospital/initial evaluation stage (ground zero) and separation of definitive abdominal wall closure (part 4) occurred as their importance became more evident. These steps can be generalized to other surgical issues beyond trauma.

\section{Evaluation)}

Ground Zero (Prehospital and Initial

The initial evaluation period can be extremely variable, and is dependent upon the presentation of the trauma patient. When possible, advanced notification of an arriving patient and initial observations by emergency response crews can allow for mobilization of resources, including preparation of operative suites, before their arrival. Commonly, the initial resuscitation is provided by large bore intravenous catheters using crystalloids. The exact end-point of resuscitation is debated. Traditionally, fluids have been given to restore normal vital parameters, but permissive hypotension, resuscitating patients to goal systolic pressure of approximately $90 \mathrm{~mm} \mathrm{Hg}$ with concomitant signs of end organ perfusion, is gaining favor, especially in patients with long transport times to definitive care 20,21 . Permissive hypotension may decrease clot disruption from increased hydrostatic pressures associated with traditional resuscitation goals. Some militaries are resuscitating patients to the presence of a palpable radial pulse and cleared neurological sensorium in austere environments 22,23

Upon arrival, a team evaluation/resuscitation effort occurs. One such model is the Advanced Trauma Life Support (ATLS) program supported by the American College of Surgeons. It is the group performing a horizontal resuscitation (as opposed to a vertical resuscitation performed with limited personnel) that allows for rapid movement of the patient through this stage. Additionally, limiting the volume resuscitation to return of basic perfusion continues until surgical control of the bleeding can be performed. Damage control resuscitation, the aggressive transfusion policy of 1:1:1 pRBC:FFP:platelets, can be combined with permissive hypotension ${ }^{20,24}$. The use of product allows for volume expansion along with function (oxygen carrying capacity, reversal of coagulopathy). The exact ratios of product have yet to be elucidated. For trauma patients, the decision for damage control surgery is often made even before arrival to the operating room.

The initial resuscitation period is altered somewhat in septic patients. It is generally a few hours, as opposed to minutes with the bleeding trauma patient, with the goal to reestablish adequate organ perfusion, not necessarily optimal organ perfusion. Once adequate preload and systemic pressure are established, the patient may proceed to operative intervention to obtain source control. Furthermore, correction of hypothermia, acidosis, and coagulopathy should be started. Vasoactive medication, while not a replacement for appropriate volume resuscitation, is often needed in these patients. In the next iteration of the Surviving Sepsis Campaign, norepinephrine will be the first line pressor, while epinephrine is the second line agent. Vasopressin remains as adjunct in sepsis for relative vasopressin deficiency. Additionally, a more aggressive volume resuscitation will be advocated.

\section{Part 1 (Initial Laparotomy)}

The next stage focuses on control of ongoing hemorrhage and visceral contamination using an abbreviated laparotomy before the depletion of the patient's physiologic reserve and initiation of the acquired coagulopathy that develops. A host of techniques exists to control bleeding sources, including the use of temporary shunts to allow for restoration of flow during the ICU resuscitation stage before definitive repair later 25-28. These shunts have gained even more popularity since their successful use in the Iraqi war. Visceral contamination control can often be attained using simple suturing or stapling techniques to control defects or rapidly removed injured segments. Definitive repair, reestablishing intestinal continuity, stoma formation, and feeding ostomies are avoided at this time. Biliary and pancreatic injuries often require external drainage with closed suction systems.

Temporary abdominal closures (TAC) using vacuum assisted abdominal dressing (Barker technique abdominal dressings) are used for a multitude of reasons now ${ }^{13}$. Besides being quick, they allow for rapid reentry into the abdominal cavity while preserving fascial integrity for latter definitive closure. The closure reduces tension to avoid subsequent abdominal compartment syndrome. Additionally, effluent from the abdominal cavity can be quantified and controlled. Given the versatility of this abdominal closure, it has generally replaced the other temporary closures, such as towel clip closures or Bogota bag. The Barker style closure can be created from common material, but commercial kits have been developed which may improve effluent evacuation/control ${ }^{29-31}$. 
In the septic abdomen, the initial surgical treatment focusses on source control using a combination of resection and/or wide drainage. Failure to achieve source control will lead to death. The exact techniques used depend upon the etiology, such as hollow viscus, hepatobiliary, or pancreatic. As with damage control for trauma, a vacuum assisted TAC has many useful properties, including helping in control the septic source with wide drainage. Additionally, abdominal compartment syndrome is common in these patients with an aggressive resuscitation. Use of this dressing type reduces this risk, and is probably a major factor in the improvement in mortality seen in this patient population.

\section{Part 2 (ICU Resuscitation)}

After the abbreviated laparotomy, the focus should be an aggressive resuscitation in the intensive care unit (ICU). While the main goals have been reversal of acidosis, hypothermia and coagulopathy, this can be accomplished by support of the patient's physiology and appropriate resuscitation in both trauma and septic abdomen patients. With surgical control of bleeding, a more aggressive volume resuscitation can occur. Twenty years ago, correction of the vitals with large volumes of crystalloid and product occurred to obtain this goal, often to supraphysiological volumes. With more understanding of resuscitation and consequences of large volume resuscitation, a more focused resuscitation is performed today. Currently, the goal should be as close to euvolemia as possible with end organ perfusion, often with liberal use of blood products. Secondly, since no single endpoint of resuscitation is capable of determining the resolution of the shock state, it should continue until multiple methods of evaluation indicate its resolution. Care should be taken during the resuscitation to support the patient's core temperature, especially with use of blood products to correct the patient's coagulopathy and anemia. With an appropriate resuscitation, the acidosis, hypothermia, and coagulopathy associated with trauma should reverse.

A host of products has been developed in the last two decades to help attain a better resuscitation. These include a multitude of devices to monitor the patient's volume status during resuscitation, like the volumetric pulmonary artery catheter and arterial pulse contour analysis, and rewarm the patient, like both external and internal heat exchange devices. Additionally, a multitude of products has been developed for both localized hemostasis and global reversal of coagulopathy to various levels of success.

During this time period, better understanding of other issues has occurred. The management of the ventilator and prevention of ARDS is a prime example. One interpretation of the ARDSnet study would be that traditional ventilator settings were inducing injury to the lungs 32 . Additionally, a multitude of ventilator modes have been developed and commercialized to provide better lung protective capabilities in the ICU. Sedation and paralytic use has declined to reduce the incidence of ICU polyneuropathy ${ }^{33-35}$. Tighter glycemic control has become commonplace in the last decade, but even this concept has evolved since its inception ${ }^{36,37}$. The development of new resuscitation strategies along with better global management of the patient's physiology are the true cornerstones for the success of damage control surgery.

Finally, monitoring for abdominal compartment syndrome development needs to be performed. Failure to recognize this clinical entity is often lethal. A better understanding of this clinical entity has occurred in the last two decades, leading to improved survival of both trauma and septic patients receiving an aggressive resuscitation.

\section{Repair)}

\section{Part 3 (Subsequent Laparotomy/Definitive}

After resuscitation in the ICU has allowed the patient to regain physiologic reserve, generally in 24 to 48 hours, definitive repair can be undertaken. Since its initial presentation, a more regimented approach has been developed for guiding the subsequent laparotomy (Table 2). One advantage of damage control surgery over the traditional approach is the possibility of regaining intestinal continuity in colonic injuries ${ }^{38}$. Before damage control surgery, these injuries would have been uniformly treated with an ostomy.

In the septic abdomen patient, the subsequent laparotomy focusses on definitive control of the septic source, again using debridement and drainage of the process. One of the major problems in evaluating the effectiveness of damage control surgery in the septic abdomen patient is how one defines 'damage control' in the studies ${ }^{14,39-44}$. Those with open abdomens due to needing to avoid abdominal compartment syndrome and loss of physiologic reserve represent true damage control surgery. Those receiving an on demand relaparotomy (relaparotomy for clinical deterioration or failure to advance) or planned relaparotomy (reoperation regardless of clinical status) after having source control and abdominal closure at the first operation are often included with the true damage control

Table 2 - $\quad$ Sequence of Definitive Repair (part 3).

1. Careful removal of packs

2. Inspection/identification of all injuries

3. Control of remaining errant bleeding points

4. Definitive gastrointestinal repair

5. Thorough abdominal washout

6. Avoid stomas and tube enterostomies, if possible

7. Nasoenteric feeding tube placement

8. Closed suction drainage, if needed

9. Temporary versus definitive abdominal wound closure

10. Tracheostomy, if needed

11. Radiographic evaluation of abdomen for retained packing 
patients in studies. The true damage control patients are probably fundamentally different from patients who undergo an a priori planned relaparotomy or on demand relaparotomy. It is difficult to identify a superiority of one technique over another for the septic abdomen due to the multitude of definitions used in the studies. Until generally accepted definitions can be established, it will be impossible to determine the true benefit of damage control in the septic abdomen patient.

\section{Part 4 (Abdominal Wall Closure)}

Closure of the abdominal wall, which was initially considered part of the subsequent laparotomy (part 3), has evolved over the past two decades into its own part of damage control surgery for trauma. This need developed since only $40-70 \%$ of patients can be closed immediately after definitive repair. As such, temporary abdominal closures have changed over the years (Table 3 ). The optimal TAC should control the viscera while preventing additional contamination or visceral injury and control the effluent to preserve skin and soft tissue integrity. They should be simple to deploy without causing radiographic artifact. Unnecessary tension should be avoided to prevent subsequent abdominal compartment syndrome. Additionally, fusion between the visceral block and abdominal wall should be prevented. They should not be costly and actively promote closure of

Table 3 - Closure Options of Open Abdominal Wounds.

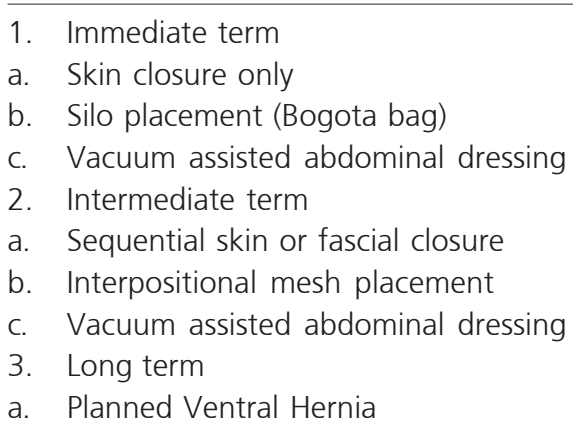

the abdominal wall. Lastly, fascial integrity should be preserved for later use (Table 4). In trauma patients, the majority of patients can achieve definitive closure; however, fascial closure rates may be lower in the septic abdomen ${ }^{45}$. Immediate use TAC's have evolved over the last few decades from simple skin closures with suture or towel clips. While quick and simple, they are rarely watertight and can cause radiographic artifacts. Silo placement (Bogota bag) did improve on this somewhat, but still fell far from optimal. Vacuum assisted abdominal wall dressings have become the predominate TAC, as they have most of the characteristics of the optimal TAC to date. The Barker style closure can be created from common operative materials, and commercial dressings (such as KCI V.A.C. and ABThera, Kinetic Concepts, Inc., San Antonio, TX; Renasys systems, Smith \& Nephew, Inc., St. Petersburg, $\mathrm{FL}$ ) have been developed for use. Additionally, prevention of fusion of the visceral block to the abdominal wall can be achieved using vacuum assisted closures, extending the time of primary fascial closure from 10 to 14 days to up to one month ${ }^{46}$

For patients that will have longer-term closure needs, interpositional mesh techniques have been developed. The meshes are attached to the fascial edges and can be tightened over time to help provide medial traction. Vacuum assisted abdominal dressings can be used in conjunction with interpositional meshes, though with more difficulty. Additionally, the absorbable meshes can be left in place to fuse with the visceral block to provide a bed for a split thickness skin graft and creation of a planned ventral hernia if definitive closure cannot be achieved. This planned ventral hernia can be reversed in six to twelve months, once the visceral block has separated from the surface tissues.

\section{Outcomes}

In large series, damage control surgery has shown a survival rate of approximately $60 \%$, compared to the $11 \%$ survival rate of conventionally treated patients in Rotondo and Schwab's initial study. In lower energy

Table 4 - $\quad$ Characteristics of the Optimal Temporary Abdominal Closure.

1. Control the abdominal viscera

2. Prevent additional contamination of the peritoneal cavity

3. Prevent injury to the abdominal viscera

4. Control and quantify the effluent

5. Preserve skin and soft tissue integrity

6. Avoid radiographic artifacts that could complicate other diagnostic and therapeutic modalities

7. Avoid tension that could lead to abdominal compartment syndrome

8. Prevent fusion of the visceral block to the abdominal wall

9. Promote medialization of the fascial edges

10. Preserve fascial integrity for later definitive native tissue closure

11. Ease of placement

12. Not costly 
mechanisms like stabbings, rates as high as $90 \%$ have been reported. Moreover, Duchesne has recently reported improved outcomes with the addition of damage control resuscitation to damage control surgery $(74 \% \text { vs. } 55 \%)^{47}$ However, damage control surgery is not without its own complications.

Abdominal compartment syndrome can be commonplace in both traumatic injury and the septic abdomen patient given the aggressive resuscitations both receive. However, with the rise in its incidence, alternative treatment modalities have been developed to combat it. Additionally, actively seeking prevention (by using open abdomen techniques like vacuum assisted dressings) is probably the main reason damage control surgery improves outcomes with the septic abdomen ${ }^{13,19}$.

Enterocutaneous fistulae are more common with damage control surgery, due to increased manipulation of the viscera. Up to $15 \%$ of trauma patients may experience this complication, with higher rates reported in septic abdomen patients ${ }^{44,45,48}$. Additionally, these fistulae tend to be the more aggressive entero-atmospheric type, which have lower spontaneous closure rates and more difficult wound contamination control issues.

Intraabdominal abscess (IAA) rates vary considerably in the trauma literature (10 to $70 \%$ ), and appear to large correlate with the use of intraabdominal packing, especially when the duration of packing exceeds 72 hours. While more frequent washouts of the peritoneal cavity may decrease IAA rates, the increased bowel manipulation leads to increased enterocutaneous fistula rates. In the septic abdomen patient, the development of tertiary peritonitis (a persistent or recurrent intraabdominal infection despite adequate initial surgical source control) appears to be approximately $20 \%$; however, even this rate has considerable variability in the literature due to numerous definitions in use ${ }^{49-51}$. Luckily, the advancement of interventional radiology allows for relatively easier control of this complication using percutaneous drains compared to historical surgical drainage procedures.

\section{Control Sequence \\ Modifications of the Traditional Damage}

At its core, damage control surgery attempts to identify those patients incapable of undergoing a definitive surgery due to loss of physiologic reserve and exchange an improvement in survival for increased morbidity. Its success in trauma patients has led it to being modified to other surgical emergencies with similar hemodynamic instabilities. These include emergent vascular and gynecological procedures. However, orthopedics and the septic abdomen (including pancreatitis complications) are the most researched.
Surgical stabilization of fractures has changed significantly over the past six decades. Before the 1950's, patients were considered too sick to operate upon. This shifted radically to the 1980's, when the benefits of immediate surgical stabilization (early total care) were realized. However, while an overall improvement in patient care with earlier mobilization, decreased complications, and reduced hospital time was seen, some populations were noted to have increased pulmonary complications and multisystem organ failure with stabilization of long bone fractures. The term damage control orthopedics, coined in 1999 by Scalea and Pollak, describes the process of using external fixation initially and delaying definitive repair until the inflammatory state has resolved in patients with exhausted physiology or multisystem trauma with a primed inflammatory state on presentation ${ }^{52-54}$.

The use of damage control surgery in the septic abdomen has been described throughout this manuscript. While some modification is needed, the essential steps of damage control surgery for trauma are used in damage control surgery for the septic abdomen. The utilization of vacuum assisted abdominal dressings for TAC to provide rapid entry/exit from the peritoneal cavity, improved control of effluent and septic source, and avoidance of abdominal compartment syndrome, is probably the main reason for its success. Unfortunately, studies to date have been small with mixed populations preventing a true determination of the efficacy of damage control techniques in this population. ${ }^{14,39-44}$. Moreover, damage control surgery can also easily integrate the Surviving Sepsis guidelines.

\section{CONCLUSIONS}

Initially described in 1993 in exsanguinating truncal trauma with combined visceral injury, damage control surgery has evolved into a treatment modality for patients with life threatening conditions incapable of tolerating traditional methods. At its core, proper identification of the patient needing this approach is coupled with an abbreviated initial operation to allow for rapid progression to ICU resuscitation before definitive repair and abdominal wall closure at subsequent operations. This system is malleable to a variety of conditions, from trauma to the septic abdomen, due to its underlying simplicity. The advancement of resuscitation strategy (such as permissive hypotension and damage control resuscitation) combined with new technologies (such as new ventilator modes, hemostatic agents, and temperature regulation devices) have allowed for the transformation of multiple surgical problems. Today, for its original application, it has altered an almost uniformly lethal event to one that the majority now survives. 


\section{R E S U M O}

Em menos de vinte anos, o que começou como um conceito para o tratamento de pacientes com trauma grave do tronco e acentuada perda sanguínea tornou-se o modelo de tratamento primário para numerosos pacientes da emergência, com lesões que ameaçam à vida, incapazes de tolerar os tradicionais métodos cirúrgicos. Seus principais conceitos são de natureza simples: em primeiro lugar, adequada identificação do paciente que necessita deste modelo de tratamento; segundo, substituição do procedimento cirúrgico convencional para a operação mínima necessária; terceira, agressiva reanimação na unidade de cuidados intensivos; em quarto lugar, tratamento definitivo apenas quando o paciente estiver apto à suportá-lo. Estes princípios fundamentais podem ser empregados para uma variedade de situações de emergência, de sua aplicação original na associação de injúrias viscerais e vasculares complexas à sepse de origem abdominal e ao trauma ortopédico. Uma série de novas estratégias de reanimação e tecnologias têm sido desenvolvidas ao longo das duas últimas décadas, da hipotensão permissiva e controle de dano da reanimação à modernos ventiladores e agentes hemostáticos, que permitiram uma reanimação adequada a este modelo, com redução da morbidade. A combinação deste simples conceito com à melhor compreensão da reanimação, tem provado ser uma potente associação. Como tal, o que era considerado uma lesão quase fatal (lesão vascular e visceral combinadas) tem possibilitado a sobrevida de doentes.

Descritores: Pacientes. Ferimentos e lesões. Terapêutica. Procedimentos cirúrgicos operatórios. Controle.

\section{REFERENCES}

1. Burch JM, Ortiz VB, Richardson RJ, et al. Abbreviated laparotomy and planned reoperation for critically injured patients. Ann Surg. 1992; 215: p. 476-83; discussion 483-4

2. Stone HH, Strom PR, Mullins RJ. Management of the major coagulopathy with onset during laparotomy. Ann Surg. 1983; 197: p. 532-5.

3. Rotondo MF, Schwab CW, McGonigal MD, et al. 'Damage control': an approach for improved survival in exsanguinating penetrating abdominal injury. J Trauma. 1993; 35: p. 375-82; discussion 382-3.

4. Cinat ME, Wallace WC, Nastanski F, et al. Improved survival following massive transfusion in patients who have undergone trauma. Arch Surg. 1999; 134: p. 964-8; discussion 968-70.

5. Krishna G, Sleigh JW, Rahman H. Physiological predictors of death in exsanguinating trauma patients undergoing conventional trauma surgery. Aust N Z J Surg. 1998; 68: p. 826-9.

6. Ciesla DJ, Moore EE, Johnson JL, et al. A 12-year prospective study of postinjury multiple organ failure: has anything changed? Arch Surg. 2005; 140: p. 432-8; discussion 438-40.

7. Rotondo MF, Zonies DH. The damage control sequence and underlying logic. Surg Clin North Am. 1997; 77: p. 761-77.

8. Shapiro MB, Jenkins DH, Schwab CW, et al. Damage control: collective review. J Trauma. 2000; 49: p. 969-78.

9. Hoey BA, Schwab CW. Damage control surgery. Scand J Surg. 2002; 91: p. 92-103.

10. Johnson JW, Gracias VH, Schwab CW, et al. Evolution in damage control for exsanguinating penetrating abdominal injury. J Trauma. 2001; 51: p. 261-9; discussion 269-71.

11. Porter JM, Ivatury RR, Nassoura ZE. Extending the horizons of "damage control" in unstable trauma patients beyond the abdomen and gastrointestinal tract. J Trauma. 1997; 42: p. 559-61.

12. Pape HC, Giannoudis $P$, Krettek $C$. The timing of fracture treatment in polytrauma patients: relevance of damage control orthopedic surgery. Am J Surg. 2002; 183: p. 622-9.

13. Schecter WP, Ivatury RR, Rotondo MF, et al. Open abdomen after trauma and abdominal sepsis: a strategy for management. J Am Coll Surg. 2006; 203: p. 390-6.

14. Stawicki SP, Brooks A, Bilski T, et al. The concept of damage control: extending the paradigm to emergency general surgery. Injury. 2008; 39: p. 93-101.

15. Waibel BH, Rotondo MF. Damage control for intra-abdominal sepsis. Surg Clin North Am. 2012; 92: p. 243-57, viii.

16. Holcomb JB, Helling TS, Hirshberg A. Military, civilian, and rural application of the damage control philosophy. Mil Med. 2001; 166: p. $490-3$
17. Eiseman B, Moore EE, Meldrum DR, et al. Feasibility of damage control surgery in the management of military combat casualties. Arch Surg. 2000; 135: p. 1323-7.

18. Blackbourne LH. Combat damage control surgery. Crit Care Med. 2008; 36: p. S304-10.

19. Cheatham ML, Safcsak K. Is the evolving management of intraabdominal hypertension and abdominal compartment syndrome improving survival? Crit Care Med. 2010; 38: p. 402-7.

20. Holcomb JB. Damage control resuscitation. J Trauma. 2007; 62: p. S36-7.

21. Soreide $E$, Deakin CD. Pre-hospital fluid therapy in the critically injured patient-a clinical update. Injury. 2005; 36: p. 100110.

22. Rhee $P$, Koustova E, Alam HB. Searching for the optimal resuscitation method: recommendations for the initial fluid resuscitation of combat casualties. J Trauma. 2003; 54: p. S52-62.

23. Dawes R, Thomas GO. Battlefield resuscitation. Curr Opin Crit Care. 2009; 15: p. 527-35.

24. Beekley AC. Damage control resuscitation: a sensible approach to the exsanguinating surgical patient. Crit Care Med. 2008; 36: p. S267-74.

25. Chambers LW, Green DJ, Sample K, et al. Tactical surgical intervention with temporary shunting of peripheral vascular trauma sustained during Operation Iraqi Freedom: one unit's experience. J Trauma. 2006; 61: p. 824-30.

26. Reilly PM, Rotondo MF, Carpenter JP, et al. Temporary vascular continuity during damage control: intraluminal shunting for proximal superior mesenteric artery injury. J Trauma. 1995; 39: p. 757-60.

27. Rasmussen TE, Clouse WD, Jenkins DH, et al. The use of temporary vascular shunts as a damage control adjunct in the management of wartime vascular injury. J Trauma. 2006; 61: p. 8-12; discussion 12-5.

28. Glass GE, Pearse MF, Nanchahal J. Improving lower limb salvage following fractures with vascular injury: a systematic review and new management algorithm. J Plast Reconstr Aesthet Surg. 2009; 62: p. 571-9.

29. Schein M, Saadia R, Jamieson JR, et al. The 'sandwich technique' in the management of the open abdomen. Br J Surg. 1986; 73: p. 369-70.

30. Brock WB, Barker DE, Burns RP. Temporary closure of open abdominal wounds: the vacuum pack. Am Surg. 1995; 61: p. 30-5.

31. Barker DE, Green JM, Maxwell RA, et al. Experience with vacuumpack temporary abdominal wound closure in 258 trauma and general and vascular surgical patients. J Am Coll Surg. 2007; 204: p. 784-92; discussion 792-3. 
32. Network TARDS. Ventilation with lower tidal volumes as compared with traditional tidal volumes for acute lung injury and the acute respiratory distress syndrome. The Acute Respiratory Distress Syndrome Network. N Engl J Med. 2000; 342: p. 1301-8.

33. Hall JB, Schweickert W, Kress JP. Role of analgesics, sedatives, neuromuscular blockers, and delirium. Crit Care Med. 2009; 37: p. S416-21.

34. de Jonghe B, Lacherade JC, Sharshar T, et al. Intensive care unitacquired weakness: risk factors and prevention. Crit Care Med. 2009; 37: p. S309-15.

35. Murray MJ, Cowen J, DeBlock H, et al. Clinical practice guidelines for sustained neuromuscular blockade in the adult critically ill patient. Crit Care Med. 2002; 30: p. 142-56.

36. Van den Berghe $G$, Wouters $P$, Weekers $F$, et al. Intensive insulin therapy in the critically ill patients. N Engl J Med. 2001; 345: p. 1359-67.

37. Van den Berghe $G$, Schetz M, Vlasselaers D, et al. Clinical review: Intensive insulin therapy in critically ill patients: NICE-SUGAR or Leuven blood glucose target? J Clin Endocrinol Metab. 2009; 94: p. 3163-70.

38. Miller PR, Chang MC, Hoth JJ, et al. Colonic resection in the setting of damage control laparotomy: is delayed anastomosis safe? Am Surg. 2007; 73: p. 606-9; discussion 609-10.

39. Adkins AL, Robbins J, Villalba M, et al. Open abdomen management of intra-abdominal sepsis. Am Surg. 2004; 70: p. 137-40; discussion 140.

40. Schein M. Planned reoperations and open management in critical intra-abdominal infections: prospective experience in 52 cases. World J Surg. 1991; 15: p. 537-45.

41. Cipolla J, Stawicki SP, Hoff WS, et al. A proposed algorithm for managing the open abdomen. Am Surg. 2005; 71: p. 202-7.

42. Finlay IG, Edwards TJ, Lambert AW. Damage control laparotomy. Br J Surg. 2004; 91: p. 83-5.

43. Horwood J, Akbar F, Maw A. Initial experience of laparostomy with immediate vacuum therapy in patients with severe peritonitis. Ann R Coll Surg Engl. 2009; 91: p. 681-7.

44. Christou NV, Barie PS, Dellinger EP, et al. Surgical Infection Society intra-abdominal infection study. Prospective evaluation of management techniques and outcome. Arch Surg. 1993; 128: $p$ 193-8; discussion 198-9.

45. Tsuei BJ, Skinner JC, Bernard AC, et al. The open peritoneal cavity: etiology correlates with the likelihood of fascial closure. Am Surg. 2004; 70: p. 652-6.
46. Miller PR, Thompson JT, Faler BJ, et al. Late fascial closure in lieu of ventral hernia: the next step in open abdomen management. J Trauma. 2002; 53: p. 843-9.

47. Duchesne JC, Kimonis K, Marr AB, et al. Damage control resuscitation in combination with damage control laparotomy: a survival advantage. J Trauma. 2010; 69: p. 46-52.

48. Anderson O, Putnis A, Bhardwaj R, et al. Short- and long-term outcome of laparostomy following intra-abdominal sepsis. Colorectal Disease. 2011; 13: p. e20-32.

49. Calandra T, Cohen J, International Sepsis Forum Definition of Infection in the ICUCC. The international sepsis forum consensus conference on definitions of infection in the intensive care unit Crit Care Med. 2005; 33: p. 1538-48.

50. Buijk SE, Bruining HA. Future directions in the management of tertiary peritonitis. Intensive Care Med. 2002; 28: p. 1024-9.

51. Evans HL, Raymond DP, Pelletier SJ, et al. Diagnosis of intraabdominal infection in the critically ill patient. Curr Opin Crit Care. 2001; 7: p. 117-21.

52. Scalea TM. Optimal timing of fracture fixation: have we learned anything in the past 20 years? J Trauma. 2008; 65: p. 253-60.

53. Pape H-C, Tornetta P, 3rd, Tarkin I, et al. Timing of fracture fixation in multitrauma patients: the role of early total care and damage control surgery. Journal of the American Academy of Orthopaedic Surgeons. 2009; 17: p. 541-9.

54. Pape $\mathrm{H}-\mathrm{C}$. Effects of changing strategies of fracture fixation on immunologic changes and systemic complications after multiple trauma: damage control orthopedic surgery. Journal of Orthopaedic Research. 2008; 26: p. 1478-84.

Recebido em 14/02/2012

Aceito para publicação em 15/03/2012

Conflito de interesse: nenhum

Fonte de financiamento: nenhuma

\section{Como citar este artigo:}

Waibel BH, Rotondo MF. Damage control surgery: it's evolution over the last 20 years. Rev Col Bras Cir. [periódico na internet] 2012; 39(4). Disponível em URL: http://www.scielo.br/rcbc

\section{Correspondence address:}

Brett Waibel

Email: brett.waibel@vidanthealth.com; rotondom@ecu.edu 